\title{
Patch repair of congenital diaphragmatic hernia is not at risk of poor outcomes
}

Etienne Suply ${ }^{1}$, Clare Rees ${ }^{1}$, Kate Cross $^{1}$, Hesham Elagami ${ }^{1}$, Simon Blackburn ${ }^{1}$, Stefano

Giuliani $^{1}$, Rashmi D’Souza ${ }^{2}$, Anna L David ${ }^{2,3,4}$, Jan Deprest ${ }^{2,3,4}$, Joe Curry ${ }^{1}$, Simon Eaton ${ }^{1}$, Paolo De Coppi ${ }^{1,4,5}$

1. General Surgery, Great Ormond Street Hospital, NHS Foundation Trust, London UK

2. Fetal Medicine Unit, University College London Hospital NHS Foundation Trust

3. Centre for Prenatal Therapy, Institute for Women's Health, UCL

4. Academic Department of Development and Regeneration, Cluster Woman and Child, Biomedical Sciences KU Leuven, Leuven, Belgium

5. Stem Cells and Regenerative Medicine Section, UCL Great Ormond Street Institute of Child Health, London, UK

Declaration of interest: none

$\wedge^{\wedge}$ Correspondence should be addressed to:

Paolo De Coppi, MD, PhD

Stem Cells and Regenerative Medicine Section,

UCL Great Ormond Street Institute of Child Health

30 Guilford Street, London WC1N 1EH, UK

Tel. +44(0)2079052808,

Fax. $+44(0) 2074046181$

Email: p.decoppi@ucl.ac.uk 


\section{$\underline{\text { ABSTRACT }}$}

\section{$\underline{\text { Purpose }}$}

Recurrence of congenital diaphragmatic hernia $(\mathrm{CDH})$ was retrospectively evaluated after correction with or without a patch in an institution where tension-free repair is advocated.

\section{$\underline{\text { Methods }}$}

Demographics and outcomes of patients with a postero-lateral CDH repaired (2000-2016) were analysed (univariate tests and binary logistic regression adjusting for time since start of study, gender, defect side, liver herniation, patch, surgical approach, absence of postero-lateral rim and length of follow-up).

\section{$\underline{\text { Results }}$}

Of 203 patients, 107 received a patch (P), and 96 were not patched (NP). Groups were not different for gestational age birthweight, gender, defect side and minimally-invasive approach rate. Preoperative ECMO incidence (P:29.9\% vs. NP:2.1\%, $\mathrm{p}<0.01)$, liver herniation (P:57.0\% vs. NP:22.9\%, $\mathrm{p}<0.01)$ and absence of a postero-lateral rim (P:61.7\% vs. NP:8.3\%, $<<0.01)$ were higher in the $\mathrm{P}$ group. The mortality rate was $10.8 \%$ (P:15.0\% vs. NP:6.2\%, $\mathrm{p}=0.07$ ). Recurrence was not different (P:9.3\% vs. NP:4.2\%, $\mathrm{p}=0.15)$. Multivariate analysis showed that recurrence was higher after thoracoscopy compared to open $(\mathrm{OR}=12.2$ [2.2-68], $\mathrm{p}<0.01)$; neither the use of patch $(\mathrm{OR}=2.3,[0.5-10.4], \mathrm{p}=0.28)$ nor any other factors were associated with recurrence.

\section{Conclusion}

In this single centre series where tension-free repair was advocated, patch repair of CDH was not associated with higher recurrence, though access route was.

Keywords: congenital diaphragmatic hernia, recurrence, patch

Levels of evidence : level III cohort study 


\section{Introduction}

Long-term outcomes of postero-lateral congenital diaphragmatic hernia $(\mathrm{CDH})$ repair has improved constantly. While prenatal strategies aim to decrease pulmonary consequences of the defect [1], surgeons should have a particular interest in reducing the rate of post-operative recurrence leading to redo surgery.

The recurrence of a $\mathrm{CDH}$ is either asymptomatic and diagnosed on a routine $\mathrm{X}$-Ray or because of potentially life-threatening symptoms including respiratory distress, small bowel obstruction, and intestinal perforation. Several factors have been described in the literature to be associated with recurrence, including the nature of the defect [2,3] (large, right, absence of peripheral rim), associated conditions (severe pulmonary hypertension) and the surgical approach (use of patch, minimally-invasive approach). The $\mathrm{CDH}$ study group has therefore proposed a classification of the defect (from A: small to D: agenesia) that is correlated to the severity (associated anomalies, mortality) [4,5]. Historically, patch were typically placed if the defect was too large for a primary repair (even under tension). This strategy was supported by studies reporting higher rates of recurrence, bowel obstruction and long term skeletal deformity in patients with large defects [6,7]. On the other side, a tension-free repair, avoiding muscular injuries and subsequent weaknesses would represent an alternative in order to prevent recurrences but implies more frequently the use of a patch [8].

Minimally-invasive surgical repair is another debated issue. With the objective to decrease the hospital length of stay, the rate of intra-abdominal complications, i.e., adhesions and subsequently small bowel obstruction events, this alternative access was described two decades ago. The thoracoscopy provide a manageable working space which can be maintained at a low pressure once the viscera are reduced in the abdomen as opposed to the laparoscopy. However, some studies reported a higher risk of recurrence with this approach which could represent a step back compared to open abdominal repair $[9,10]$. 
Thus, this study aims to evaluate a single institution experience where a tension-free repair has been advocated for more than 17 years comparing the outcomes of patients in whom $\mathrm{CDH}$ was repaired with or without a patch. 


\section{Method}

After approval of the local audit department, we conducted a single centre retrospective study. All consecutive patients who underwent a surgical repair of a postero-lateral CDH in our department (tertiary centre) between January 2000 and December 2016 were included. The surgery was conducted by an experienced senior surgeon (a total of 9 surgeons over the period, no predisposition for the use of a patch). We did not include though patients who had a previous repair in other centres, patients who died before any surgical repair and patients presenting with an anterior diaphragmatic hernia (Morgagni-Larrey). The surgery was conducted after stabilization and performed either by ipsilateral transverse muscle cutting laparotomy, posterolateral cutting muscle thoracotomy, open laparoscopy ( 3 or 4 ports, $5 \mathrm{~mm}$ scope, $3 \mathrm{~mm}$ set of instruments) or open thoracoscopy ( 3 or 4 ports, $5 \mathrm{~mm}$ scope, $3 \mathrm{~mm}$ set of instruments). Once the viscera were reduced in the abdominal cavity, the defect was assessed and closed with interrupted non-absorbable stitches in a tension-free manner. A patch was used to avoid a repair under tension. In absence of a peripherical rim, pericostal stitches were performed. At the discretion of the surgeon in charge, the mesentery root was widened ( \pm associated with appendectomy) in case of a malrotation potentially at risk of volvulus. The perioperative medical management was conducted initially in neonatal/paediatric intensive care unit, then in a standard paediatric ward following good practices.

Data were collected through the electronic record system and all operative notes were reviewed. Data collected, if applicable, regarded: date of birth, gestational age at birth, date of surgery, late presenter (after 30 days of life), gender, prenatal diagnosis, lung-to-head ratio, prenatal herniation of the liver and/or the stomach in the chest, pre-operative extra corporeal membrane oxygenation (ECMO), pre-operative pulmonary hypertension (need of specific therapies), Apgar score at 5 minutes, elective intubation at birth, genetic condition, congenital 
cardiac anomalies, operative technique (laparotomy, laparoscopy, thoracotomy, thoracoscopy), side and size of the defect, the use of a patch (size, material), the position of the liver during surgery, the absence of a postero-lateral rim, the need of stitches around ribs, the widening of the mesenteric root, appendectomy, additional surgeries during the follow-up, the occurrence of necrotizing enterocolitis, recurrence of $\mathrm{CDH}$ and the date of redo surgery, death and date of death, occurrence of small bowel obstruction during the follow-up, the date of the last clinic appointment. Missing data regarded only continuous data and are mentioned in legends.

Medical conditions and outcomes of patients repaired with or without patch were analysed first using univariate tests (Fisher exact test or parametric or non-parametric t-test as appropriate -normality assessed with the Shapiro-Wilk test-, Prism v7 software) followed by a binary logistic regression adjusting for time since start of study (date of operation), gender, side of defect, liver up, use of a patch, surgical approach, absence of a postero-lateral rim and length of follow-up using IBM SPSS v24 software. A p value lesser than 0.05 was considered to be significant. Data are presented as mean, median (min-max) or percentage as appropriate. 


\section{Results}

Over this 17-year period, 203 patients underwent primary repair of a $\mathrm{CDH}$ at our institution (flow chart in figure 1), 107 with a patch (P), 96 without (NP). A delayed presentation was present in $28(13.8 \%)$ patients, who were operated upon at a median age of 196 [28-2166] days. There were 175 cases repaired neonatally, of whom 95 patients (46.8\%) were diagnosed prenatally at a gestational age of 21 [16-39] weeks. These were overrepresented in the P-group than in the non-NP-patch group $(66.3 \%$ vs $25.0 \%$ respectively, $\mathrm{p}<0.01)$. The defect was located on the left in $79.3 \%$ patients.

At birth (table 1), patients from both groups were not different in terms of gestational age at birth, birthweight. Apgar score was higher in the NP group than in the P group (mean 8.2 [2-10] vs 7.5 [2-10]; $p=0.03)$. In case of prenatal diagnosis, an immediate intubation before 5 min was performed in $48(50.5 \%)$ patients. A genetic condition was found in $11(5.4 \%)$ patients (Trisomy 21, 18 and 22q11 del), a congenital cardiac anomaly in 12 (5.9\%). Patients repaired with a patch had more frequently with a pre-operative suprasystemic pulmonary hypertension than non-patched patients $(57.9 \%$ vs $21.8 \%$, respectively, $\mathrm{p}<0.01)$ and had more frequently ECMO $(29.9 \%$ vs $2.1 \%$, respectively, $\mathrm{p}<0.01)$.

The surgery (table 2) was conducted at a median age of 7 [0-2166] days, and at 6 [0374] days for patient with a neonatal presentation. From the operative notes, we retrospectively evaluated the size of the defect and defined it following the $\mathrm{CDH}$ group classification [11]. A defect type A was found in 63 patients, a B in 58, a C in 66 and a D in 16 cases (table 2). A diaphragmatic rim was more frequently absent in patients repaired with a patch than without $61.7 \%$ vs $8.3 \%$, respectively, $\mathrm{p}<0.01$ ) as was the per-operative liver herniation in the thorax (57.0\% vs $22.9 \%$, respectively, $\mathrm{p}<0.01)$. The repair was performed via laparotomy in 155 patients, thoracotomy in 1, laparoscopy in 12 (8 conversions) and thoracoscopy in 36 patients 
(10 conversions, 7 laparotomy and 3 thoracotomy). A patch of a median diameter of $5.3 \pm 1.7$ cm was used to close the defect in 107 patients (polyethylene terephthalate 54, fibrine 1, polytetrafluoroethylen 4 , polyesther 22 , polypropylen 14 , unknown 10 ). The rate of patch use, represented in figure 2, increased over the years from $26 \%$ in 2000 to $80 \%$ in 2016 ( $<<0.01$ ). Stitches were performed around the ribs in $88(43.3 \%)$ cases, more often in P group than in NP group $(62.6 \%$ vs $21.8 \%$, respectively, $\mathrm{p}<0.01)$. In addition, the mesentery root was widened for 30 patients, associated with an additional prophylactic appendectomy as a part of the Ladd's procedure.

During the post-operative period, 4 episodes of NEC were diagnosed (3 treated medically and 1 operated for small bowel perforation). A laparotomy was performed in 3 patients for a pyloroplasty, for a duodenal perforation and for a duodenal obstruction.

Outcomes are represented in table 3. The follow-up period was comparable in both groups, as well as the recurrence rate $(9.3 \%$ in the $\mathrm{P}$ versus $4.2 \%$ in the non-P, $\mathrm{p}=0.17)$. The delay for the diagnosis of recurrence seemed higher after patch repair (424 [64-2329]) than after primary repair (10 [24-174]) but was not statistically different $(\mathrm{p}=0.067)$. The incidence of recurrence by follow up period is illustrated in figure 2. A higher recurrence rate was seen between 2008 and 2012 in both groups. Among the 7 recurrences that occurred in nonconverted thoracoscopic repaired patients $(n=26), 5$ happened between 2007 and 2008 (13 thoracoscopic repairs during this period). An episode of small bowel obstruction requiring a surgery was noticed in eight patients including three in the $\mathrm{P}$ group. Five patients required an additional fundoplication for severe gastro-oesophageal reflux and two patients had an additional Ladd's procedure for malrotation. During the follow up period, the mortality rate was $10.8 \%, 15.0 \%$ after patch repair and $6.2 \%$ in the NP group $(\mathrm{p}=0.07)$. After patch repair, the majority ( $\mathrm{n}=10 / 16,62.5 \%$ ) of infants died beyond 100 days of life as opposed to the patients deceased in the NP-group who (5/6) 83.3\% died within the first month of life. 
Multivariate analysis using a binary logistic regression showed that recurrence was higher after thoracoscopic repair compared to open (OR 12.2 [2.2-68], $\mathrm{p}<0.01$ ); neither the use of patch $(\mathrm{OR} 2.3,[0.5-10.4], \mathrm{p}=0.28)$ nor any other factors were significant predictors of recurrence. Interestingly, we have observed this is possibly related to a learning curve with overall increase of recurrence free rate thoracoscopic repair for $\mathrm{CDH}$ repair with time (Figure 4).

We separately analysed outcomes of patients who had a prenatal assessment in our institution $(\mathrm{n}=52)$. Only one patient underwent a FETO procedure. The lung-to-head ratio (LHR) at presentation to the foetal medicine unit was measured at $1.3[0.25-4.57]$ and the location of the liver and the stomach (chest or abdomen) was mentioned. The CDH Study Group score, main surgical findings and outcomes are summarised in the table 4 . 


\section{Discussion}

This study is, to our knowledge, the largest series of $\mathrm{CDH}$ repaired with a patch rate of over 50\%. Over the past 15 years we have observed an increasing use of patches in patients with $\mathrm{CDH}$. Because of the retrospective nature of the study, reasons could be different and maybe simply related to greater survival in high risk cases who require a patch. Reassuringly, the overall recurrence rate was low compared to previously reported data. Moreover, despite a large proportion of patients being repaired with a patch and a high incidence of factors reportedly associated with recurrence, in this group, i.e., use of ECMO before surgery, liver herniation and absence of rim [12], the recurrence rate was not statistically different.

In this study, the only factor associated with recurrence was the thoracoscopic approach. This result is consistent with previous meta-analyses $[9,10]$ and this is possibly related to a learning curve. A thoracoscopic approach is still recommended in our institution for selected patients such as infants who are very stable or who present late. One of the factors that could explain the high recurrence rate could be the underestimation of the tension during the repair with the thoracoscopy, or to persist with the minimally invasive surgery when a patch is indicated that can be technically challenging and time consuming. In a previous study, however, the insertion of a patch during a thoracoscopic repair of $\mathrm{CDH}$ has been considered safe in terms of peri-operative morbidity, even if the duration of the procedure was longer [13]. Moreover, thoracoscopy is not contraindicated in newborn infants, as a relative hypercapnia can be tolerated without adverse effect, in particular in term of neurological development [14]. The majority of recurrences observed in this study happened at the beginning of our experience with thoracoscopy and the learning process may explain such a high recurrence rate. An algorithm has been published in order to help the decision for the thoracoscopic approach in stable patients 
[15] but further analyses should be done in order to assess the learning curve for safety of a thoracoscopic approach to repair a $\mathrm{CDH}$, associated with the placement of a patch.

Another reason explaining the reluctance of certain surgeons to perform a thoracic approach is because it is almost impossible to assess hence treat small bowel malrotation. In our study, all patients operated on by an abdominal approach underwent an assessment for midgut rotation. The mesentery was widened in 30 patients at the end of the procedure. This was not done in patients with a thoracoscopic repair but none of them presented with an acute volvulus during the follow-up period. The risk of volvulus was usually assessed by an upper gastro-intestinal tract contrast study and an additional Ladd's procedure was performed if indicated. The operation was performed laparoscopically in most cases and results were reported in a recently published study[16].

The risk of recurrence has been associated with the nature of defect and associated comorbidities. The $\mathrm{CDH}$ study group proposed a classification to highlight defect types and associated these with different outcomes [17]. The hypothesis was that larger defects would be correlated with more severe forms of lung hypoplasia. Patch repair has been highlighted to be potentially associated in higher recurrence rate [12]. In our series, where patch repair was widely represented, we did not observe a statistical difference in term of recurrence between $\mathrm{P}$ and NP patients. The majority of patches we used were made of polyester, but previous studies have shown that the results were similar whatever the material $[18,19]$. The tension-free approach which was also advocated in previous studies could be involved in those results. Some authors even recommend the use of a conic or dome shape patch allowing some sort of growth [8]. Interestingly, in our study, the recurrence occurred later in the group repaired in a patch 
than in the group repaired without patch and this could be the drawback of a synthetic patch that does not grow over the time.

We had 28 cases who presented late of whom only 6 were repaired with a patch. In keeping with previous studies, this subgroup of patients seems to have better outcomes than those presenting as neonates[20]. They may present less often with pulmonary hypoplasia and/or pulmonary hypertension and usually the defect is small and easy to close. None of these patients died in the follow-up and the recurrence rate was nil.

The overall mortality in this study was $11 \%, 15 \%$ after patch repair versus $6 \%(\mathrm{p}=0.07)$. This coincides with a higher severity at presentation in the patch group, given these patients were more likely on ECMO or presented with liver herniation or with an absent peripheral rim. Interestingly, in the patch repair group, most deaths occurred after 100 days of life, probably due to the consequences of the underlying lung disease whereas in the NP group most deaths occurred within the first 3 months of life.

One of the weakness of this study, due to its retrospective nature, is the absence of a picture of the defect and the conditions of repair. While the defect type was evocated, the size of the patch was often reported in the operative note. The absence of a rim was also consistently documented but its length was not. Finally, the tension applied to the repair was not assessed specifically and this could be a way to measure the risk of recurrence. Another weakness of this study is the absence of very long-term follow-up, i.e. after the end of growth, in order to evaluate the consequences of the patch use on the occurrence of chest deformities, scoliosis and pectus excavatum [21,22]. These issues might be solved in a long-term prospective cohort specifically designed to raise these concerns. Another lead would be provided by recent 
progress in tissue engineering that raised some interesting results in animal model of CDH [23]. This could provide a patch which can grow up with the patient and therefore bring the advantages of a lower rate of complication.

In conclusion, in this single centre series, and with a liberal use of patched repairs, we observed a low recurrence rate, which was equal to that of unpatched repairs. Recurrence was higher in our early thoracoscopic experience. We suggest that use of a patch may represent a way to decrease the higher recurrence rate associated with this approach.

\section{Acknowledgments}

P.D.C. is supported by National Institute for Health Research (NIHR-RP-2014-04-046). All research at Great Ormond Street Hospital NHS Foundation Trust and UCL Great Ormond Street Institute of Child Health is made possible by the NIHR Great Ormond Street Hospital Biomedical Research Centre. The views expressed are those of the author (s) and not necessarily those of the NHS, the NIHR or the Department of Health. JD is supported by Great Ormond Street Hospital Charity fund. 


\section{References}

[1] Lansdale N, Alam S, Losty PD, Jesudason EC. Neonatal endosurgical congenital diaphragmatic hernia repair: a systematic review and meta-analysis. Ann Surg 2010;252:206. doi:10.1097/SLA.0b013e3181dca0e8.

[2] Nagata K, Usui N, Terui K, Takayasu H, Goishi K, Hayakawa M, et al. Risk factors for the recurrence of the congenital diaphragmatic hernia-report from the long-term follow-up study of Japanese CDH study group. Eur J Pediatr Surg Off J Austrian Assoc Pediatr Surg Al Z Kinderchir 2015;25:9-14. doi:10.1055/s-0034-1395486.

[3] Putnam LR, Gupta V, Tsao K, Davis CF, Lally PA, Lally KP, et al. Factors associated with early recurrence after congenital diaphragmatic hernia repair. J Pediatr Surg 2017;52:928-32. doi:10.1016/j.jpedsurg.2017.03.011.

[4] Harting MT, Lally KP. The Congenital Diaphragmatic Hernia Study Group registry update. Semin Fetal Neonatal Med 2014;19:370-5. doi:10.1016/j.siny.2014.09.004.

[5] Congenital Diaphragmatic Hernia Study Group, Morini F, Valfrè L, Capolupo I, Lally KP, Lally PA, et al. Congenital diaphragmatic hernia: defect size correlates with developmental defect. J Pediatr Surg 2013;48:1177-82. doi:10.1016/j.jpedsurg.2013.03.011.

[6] Moss RL, Chen CM, Harrison MR. Prosthetic patch durability in congenital diaphragmatic hernia: a long-term follow-up study. J Pediatr Surg 2001;36:152-4.

[7] Jancelewicz T, Vu LT, Keller RL, Bratton B, Lee H, Farmer D, et al. Long-term surgical outcomes in congenital diaphragmatic hernia: observations from a single institution. $\mathrm{J}$ Pediatr Surg 2010;45:155-60; discussion 160. doi:10.1016/j.jpedsurg.2009.10.028.

[8] Loff S, Wirth H, Jester I, Hosie S, Wollmann C, Schaible T, et al. Implantation of a cone-shaped double-fixed patch increases abdominal space and prevents recurrence of large defects in congenital diaphragmatic hernia. J Pediatr Surg 2005;40:1701-5.

doi:10.1016/j.jpedsurg.2005.07.007.

[9] Zhu Y, Wu Y, Pu Q, Ma L, Liao H, Liu L. Minimally invasive surgery for congenital diaphragmatic hernia: a meta-analysis. Hernia J Hernias Abdom Wall Surg 2016;20:297-302. doi:10.1007/s10029-015-1423-0.

[10] Weaver KL, Baerg JE, Okawada M, Miyano G, Barsness KA, Lacher M, et al. A Multi-Institutional Review of Thoracoscopic Congenital Diaphragmatic Hernia Repair. J Laparoendosc Adv Surg Tech A 2016;26:825-30. doi:10.1089/lap.2016.0358.

[11] Brindle ME, Cook EF, Tibboel D, Lally PA, Lally KP, Congenital Diaphragmatic Hernia Study Group. A clinical prediction rule for the severity of congenital diaphragmatic hernias in newborns. Pediatrics 2014;134:e413-419. doi:10.1542/peds.2013-3367.

[12] Hajer GF, vd Staak FH, de Haan AF, Festen C. Recurrent congenital diaphragmatic hernia; which factors are involved? Eur J Pediatr Surg Off J Austrian Assoc Pediatr Surg Al Z Kinderchir 1998;8:329-33. doi:10.1055/s-2008-1071226.

[13] Keijzer R, van de Ven C, Vlot J, Sloots C, Madern G, Tibboel D, et al. Thoracoscopic repair in congenital diaphragmatic hernia: patching is safe and reduces the recurrence rate. $\mathrm{J}$ Pediatr Surg 2010;45:953-7. doi:10.1016/j.jpedsurg.2010.02.017.

[14] Bishay M, Giacomello L, Retrosi G, Thyoka M, Garriboli M, Brierley J, et al. Hypercapnia and acidosis during open and thoracoscopic repair of congenital diaphragmatic hernia and esophageal atresia: results of a pilot randomized controlled trial. Ann Surg 2013;258:895-900. doi:10.1097/SLA.0b013e31828fab55.

[15] Costerus S, Zahn K, van de Ven K, Vlot J, Wessel L, Wijnen R. Thoracoscopic versus open repair of CDH in cardiovascular stable neonates. Surg Endosc 2016;30:2818-24.

doi:10.1007/s00464-015-4560-8. 
[16] Arnaud AP, Suply E, Eaton S, Blackburn SC, Giuliani S, Curry JI, et al. Laparoscopic Ladd's procedure for malrotation in infants and children is still a controversial approach. $\mathrm{J}$ Pediatr Surg 2018. doi:10.1016/j.jpedsurg.2018.09.023.

[17] Clark RH, Hardin WD, Hirschl RB, Jaksic T, Lally KP, Langham MR, et al. Current surgical management of congenital diaphragmatic hernia: a report from the Congenital Diaphragmatic Hernia Study Group. J Pediatr Surg 1998;33:1004-9.

[18] Grethel EJ, Cortes RA, Wagner AJ, Clifton MS, Lee H, Farmer DL, et al. Prosthetic patches for congenital diaphragmatic hernia repair: Surgisis vs Gore-Tex. J Pediatr Surg 2006;41:29-33; discussion 29-33. doi:10.1016/j.jpedsurg.2005.10.005.

[19] Romao RLP, Nasr A, Chiu PPL, Langer JC. What is the best prosthetic material for patch repair of congenital diaphragmatic hernia? Comparison and meta-analysis of porcine small intestinal submucosa and polytetrafluoroethylene. J Pediatr Surg 2012;47:1496-500. doi:10.1016/j.jpedsurg.2012.01.009.

[20] Bagłaj M. Late-presenting congenital diaphragmatic hernia in children: a clinical spectrum. Pediatr Surg Int 2004;20:658-69. doi:10.1007/s00383-004-1269-5.

[21] Laviola M, Zanini A, Priori R, Macchini F, Leva E, Torricelli M, et al. Thoracoabdominal asymmetry and asynchrony in congenital diaphragmatic hernia. Pediatr Pulmonol 2015;50:915-24. doi:10.1002/ppul.23081.

[22] Takayasu H, Masumoto K, Goishi K, Hayakawa M, Tazuke Y, Yokoi A, et al. Musculoskeletal abnormalities in congenital diaphragmatic hernia survivors: Patterns and risk factors: Report of a Japanese multicenter follow-up survey. Pediatr Int Off J Jpn Pediatr Soc 2016;58:877-80. doi:10.1111/ped.12922.

[23] De Coppi P, Deprest J. Regenerative medicine solutions in congenital diaphragmatic hernia. Semin Pediatr Surg 2017;26:171-7. doi:10.1053/j.sempedsurg.2017.04.009. 


\section{Figures and Tables}

7.1. Figure 1

\section{Flow chart}

265: All diagnosis of $\mathrm{CDH}$

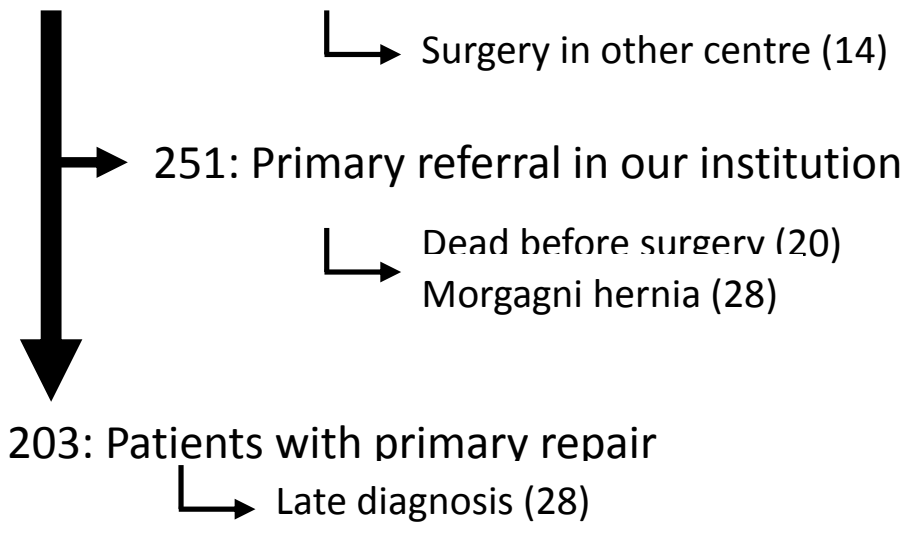

Figure 1: selection of patients for the study 
7.2.Figure 2

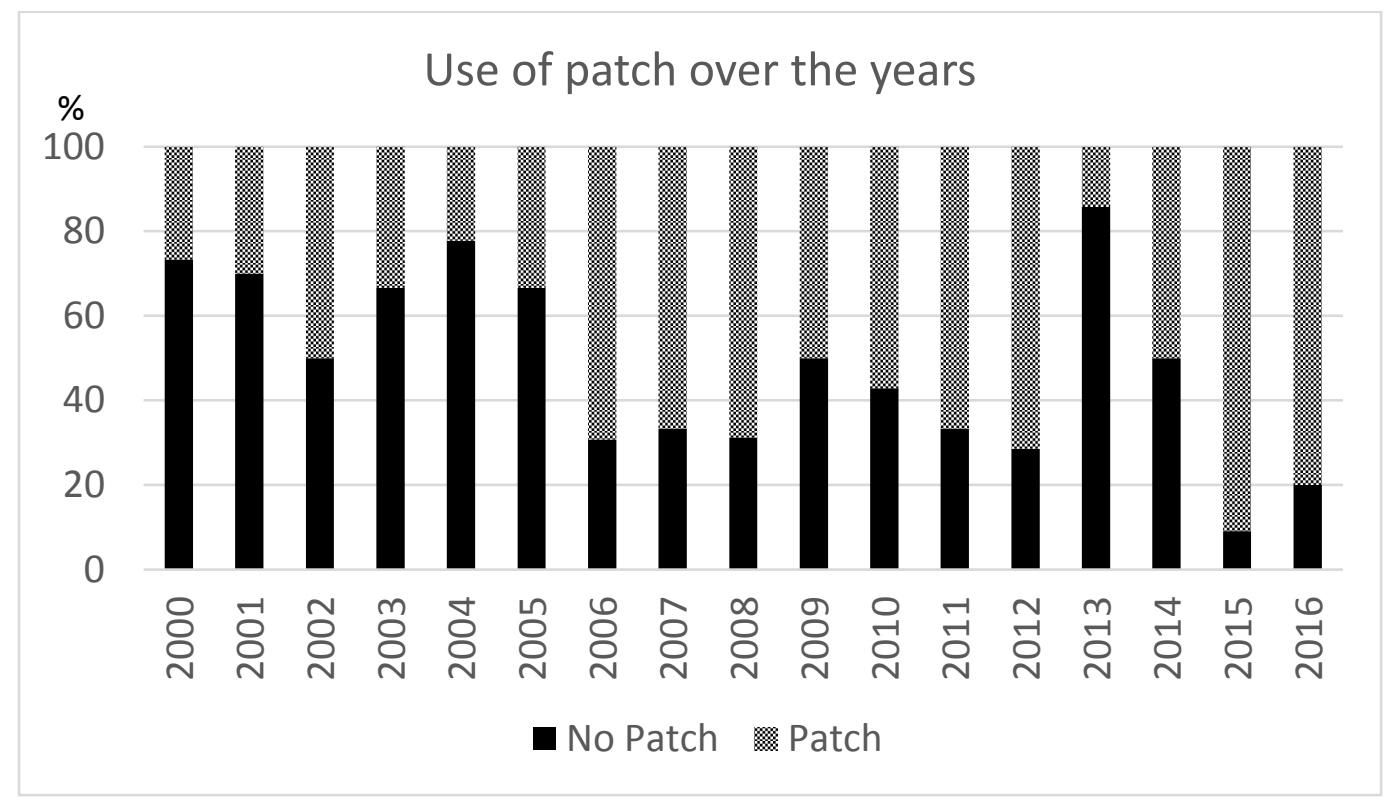

Figure 2: Incidence of patch use during the study period.

The use of a patch to repair the defect is expressed as a percentage. A significant increase of the patch repair was observed during the time of the study (Chi-square test). 


\subsection{Figure 3}

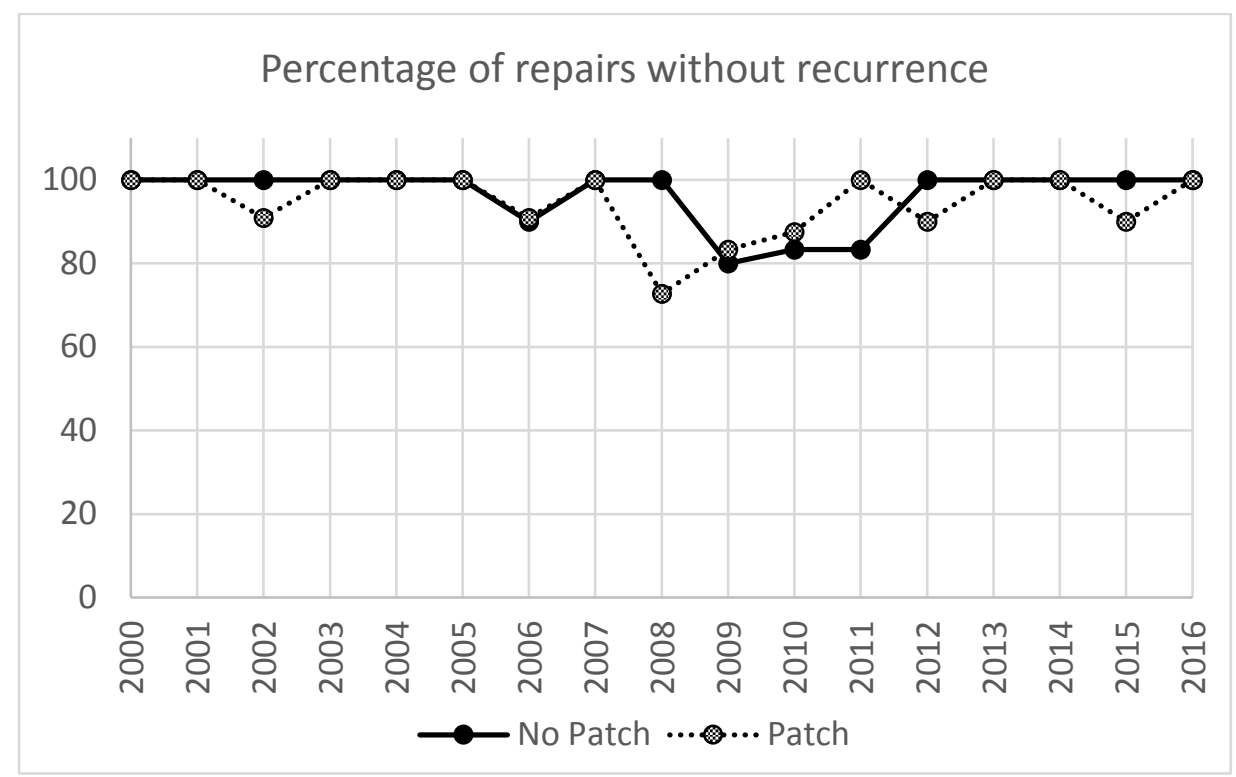

Figure 3: incidence of surgery performed without recurrence.

The graph represents the percentage of procedures non-complicated by a recurrence. There was an increased recurrence rate between 2008 and 2012, concomitant with the beginning of the thoracoscopic experience. 
7.4.Figure 4

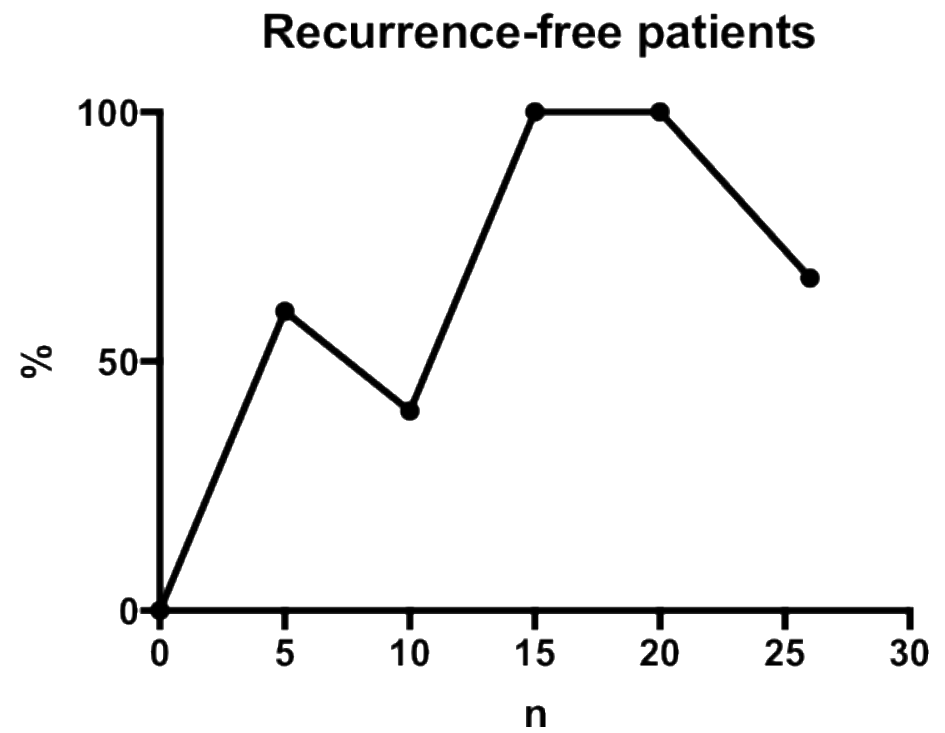

Figure 4:

Recurrence free patients who underwent a non-converted thoracoscopic repair of CDH. 
7.5.Table 1

\begin{tabular}{lcccc}
\hline & Total $(\mathrm{n}=203)$ & Patch $(\mathrm{n}=107)$ & No patch $(\mathrm{n}=96)$ & p value \\
\hline $\begin{array}{l}\text { Gestational age at birth } \\
\text { (weeks), mean (range) }\end{array}$ & $38[28-43]$ & $38[28-42]$ & $38[29-43]$ & $0.24^{\#}$ \\
\hline Birth weight, mean (range) & $3025[905-6250]$ & $2966[905-4480]$ & $3096[1270-6250]$ & $0.17^{\#}$ \\
\hline Males, n (\%) & $123(60.6)$ & $63(58.9)$ & $60(62.5)$ & $0.66^{\dagger}$ \\
\hline $\begin{array}{l}\text { Prenatal diagnosis, n (\%) } \\
\text { Neonatal diagnosis, n (\%) }\end{array}$ & $175(86.2)$ & $101(94.4)$ & $74(77.1)$ & $<0.01^{\dagger}$ \\
\hline $\begin{array}{l}\text { Preoperative ECMO, n (\%) } \\
\text { Suprasystemic pulmonary }\end{array}$ & $34(16.7)$ & $32(29.9)$ & $2(2.1)$ & $<0.01^{\dagger}$ \\
\hline \begin{tabular}{l} 
hypertension, n (\%) \\
\hline
\end{tabular}
\end{tabular}

Table 1: initial clinical presentation

\#: two-sided Mann Whitney U-test for non-normal distribution.

$\dagger^{\dagger}$ two-sided Fisher exact test

Missing data: Gestational age (P, n=4; NP, $n=4)$; Birth weight $(P, n=9 ; N P, n=12)$ 


\begin{tabular}{|c|c|c|c|c|}
\hline & $\begin{array}{c}\text { Total } \\
(\mathrm{n}=203)\end{array}$ & $\begin{array}{c}\text { Patch } \\
(\mathrm{n}=107)\end{array}$ & $\begin{array}{l}\text { No patch } \\
(\mathrm{n}=96)\end{array}$ & $\mathrm{p}$ value \\
\hline Left side, $\mathrm{n}(\%)$ & $161(79.3)$ & $80(74.8)$ & $81(84.4)$ & $0.12^{\dagger}$ \\
\hline $\begin{array}{l}\text { Age at surgery (days), median } \\
\text { (range) }\end{array}$ & $7[0-2166]$ & $10[1-2166]$ & $5[0-1662]$ & $0.013^{\#}$ \\
\hline For neonatal cases & $6[0-374]$ & $8[1-374]$ & 3 [0-296] & $<0.001^{\#}$ \\
\hline Surgery before 30 days, $\mathrm{n}(\%)$ & $170(83.7)$ & $97(90.7)$ & $73(76.1)$ & $0.007^{\dagger}$ \\
\hline $\begin{array}{c}\text { Surgical technique, } \mathrm{n}(\%) \\
\text { Laparoscopy } \\
\text { Laparotomy } \\
\text { Thoracoscopy } \\
\text { Thoracotomy }\end{array}$ & $\begin{array}{c}12(5.9) \\
154(75.9) \\
36(17.7) \\
1(0.5)\end{array}$ & $\begin{array}{c}4(3.7) \\
84(78.5) \\
19(17.7) \\
0(0.0)\end{array}$ & $\begin{array}{c}8(8.3) \\
70(72.9) \\
17(17.7) \\
1(1.0)\end{array}$ & $0.37^{\ddagger}, \circ$ \\
\hline Liver herniated, n (\%) & 83 (40.9) & $61(57.0)$ & $22(22.9)$ & $<0.001^{\dagger}$ \\
\hline Absence of rim, n (\%) & $74(36.4)$ & $66(61.7)$ & $8(8.3)$ & $<0.001^{\dagger}$ \\
\hline Stitch around the ribs, $\mathrm{n}(\%)$ & $88(43.3)$ & $67(62.6)$ & $21(21.8)$ & $<0.001^{\dagger}$ \\
\hline $\begin{array}{l}\mathrm{A}, \mathrm{n}(\%) \\
\mathrm{B}, \mathrm{n}(\%) \\
\mathrm{C}, \mathrm{n}(\%) \\
\mathrm{D}, \mathrm{n}(\%)\end{array}$ & $\begin{array}{l}63(31.0) \\
58(28.6) \\
66(32.5) \\
16(14.8)\end{array}$ & $\begin{array}{c}3(2.8) \\
30(28.0) \\
58(54.2) \\
16(14.9)\end{array}$ & $\begin{array}{c}60(62.5) \\
28(29.2) \\
8(8.3) \\
0(0.0)\end{array}$ & $<0.001^{\ddagger}$ \\
\hline
\end{tabular}

Table 2: Operative findings in the two groups .

\#: two-sided Mann Whitney U-test for non-normal distribution.

$\dagger$ : two-sided Fisher exact test

$\$$ : Chi-square test

${ }^{\circ}$ : the last row was excluded for test applicability 
7.7.Table 3

\begin{tabular}{|c|c|c|c|c|}
\hline & $\begin{array}{c}\text { Total } \\
(\mathrm{n}=203)\end{array}$ & Patch $(n=107)$ & $\begin{array}{l}\text { No patch } \\
(\mathrm{n}=96)\end{array}$ & $\mathrm{p}$ \\
\hline Recurrence, n (\%) & 14 (6.9) & $10(9.3)$ & $4(4.2)$ & $0.17^{\dagger}$ \\
\hline Delay, median (range) & 221 [10-2329] & 424 [64-2329] & 10 [24-174] & $0.067^{\#}$ \\
\hline Mortality, n (\%) & $22(10.8)$ & $16(15.0)$ & $6(6.2)$ & $0.07^{\dagger}$ \\
\hline Before 30 days, n (\%) & $8(36.4)$ & $4(25.0)$ & $4(66.6)$ & $0.14^{\dagger}$ \\
\hline After 100 days, n (\%) & $11(50.0)$ & $10(62.5)$ & $1(16.7)$ & $0.15^{\dagger}$ \\
\hline $\begin{array}{l}\text { Age of death, days median } \\
\text { (range) }\end{array}$ & 108 [7-927] & 148 [7-927] & 25 [12-370] & $0.17^{\#}$ \\
\hline Small bowel obstruction, $\mathrm{n}(\%)$ & $8(3.9)$ & $3(2.8)$ & $5(5.2)$ & $0.48^{\dagger}$ \\
\hline
\end{tabular}

Table 3: Outcomes comparisons in the two groups.

${ }^{\dagger}:$ two-sided Fisher exact test

\#: two-sided Mann Whitney U-test for non-normal distribution. 
7.8.Table 4

\begin{tabular}{|c|c|c|c|c|c|}
\hline & \multirow[t]{2}{*}{ Total } & \multicolumn{2}{|c|}{ Liver down } & \multicolumn{2}{|c|}{ Liver up } \\
\hline & & Stomach down & Stomach up & Stomach down & Stomach up \\
\hline$n$ & 52 & $8(15.4)$ & $28(53.8)$ & $5(9.6)$ & $10(19.2)$ \\
\hline $\begin{array}{l}\text { CDH Study } \\
\text { Group score } \\
\text { median, [range] }\end{array}$ & $2[0-4]$ & $1[0-4]$ & $1[0-4]$ & $2.5[2-3]$ & $2[0-3]$ \\
\hline Defect & & & & & \\
\hline $\mathrm{A}, \mathrm{n}(\%)$ & $9(17.3)$ & $3(37.5)$ & $3(10.7)$ & $0(0.0)$ & $3(30.0)$ \\
\hline $\mathrm{B}, \mathrm{n}(\%)$ & $19(36.5)$ & $4(50.0)$ & $11(39.3)$ & $2(40.0)$ & $1(10.0)$ \\
\hline $\mathrm{C}, \mathrm{n}(\%)$ & $21(40.4)$ & $1(12.5)$ & $12(42.9)$ & $3(60.0)$ & $5(50.0)$ \\
\hline $\mathrm{D}, \mathrm{n}(\%)$ & $3(5.8)$ & $0(0.0)$ & $2(7.1)$ & $0(0.0)$ & $1(10.0)$ \\
\hline Patch, n (\%) & $37(71.2)$ & $3(37.5)$ & $21(75.0)$ & $5(100.0)$ & $7(70.0)$ \\
\hline $\begin{array}{l}\text { Recurrence, } \\
\text { n }(\%)\end{array}$ & $7(13.4)$ & $0(0.0)$ & $4(14.3)$ & $0(0)$ & $3(33.3)$ \\
\hline Death, n (\%) & $7(13.5)$ & $1(12.5)$ & $1(3.6)$ & $1(20.0)$ & $4(40.0)$ \\
\hline
\end{tabular}

Table 4: Prenatal findings and outcomes

1 patient with unknown stomach position (B defect repaired with a patch) 